\title{
Rare oesophageal tumours: experience of one centre
}

\author{
J. Zielinski, W. J. Kruszewski, R. Jaworski, I. Haponiuk, N. Irga, J. Zygon, A. Kopacz, J. Jaskiewicz
}

Received: 24 July 2012 / Accepted: 16 October 2012 / Published online: 20 November 2012

(C) The Author(s) 2012. This article is published with open access at Springerlink.com.

\section{Summary}

Aim of study The aim of this study is to compare demographic and clinical data as well as applied treatment methods in patients with rare benign and malignant tumours of the oesophagus.

Methods Eight hundred and thirty patients with oesophageal cancer were treated in the Department of Surgical Oncology in 1960-2005. In 15 cases (1.8\%), rare benign $(n=11)$ or malignant $(n=4)$ types of tumours were diagnosed. Patients with rare oesophageal tumours were included in the study, excluding those with squamous cell carcinoma or adenocarcinoma of the oesophagus. Demographic and clinical data were analysed from each patient qualified for the study. Oesophageal X-rays with contrast medium, gastroscopies and, as of 1991, computed tomographies (CTs) were performed as preoperative diagnostic procedures.

Results In the postoperative histopathological examinations, all benign tumours proved to be oesophageal leiomyomas. Four different malignant tumours-a sarcoma, a neuroendocrine carcinoma, a lymphoma and a squamous cell carcinoma in a patient with Crohn's disease, were diagnosed in the other four patients. In a group of 15 patients with rare oesophageal tumours

J. Zielinski, MD, PhD ( $ه) \cdot$ J. Zygon, MD · A. Kopacz, MD, PhD · J. Jaskiewicz, MD, PhD

Department of Surgical Oncology, Medical University of Gdansk, Smoluchowskiego 17, 80-214 Gdansk, Poland e-mail: jaziel@gumed.edu.pl

W. J. Kruszewski, MD, PhD

Division of Oncology Propaedeutics, Medical University

of Gdansk, Gdansk, Poland

R. Jaworski, MD, PhD $\cdot$ I. Haponiuk, MD, PhD

Department of Pediatric Cardiac Surgery, Pomeranian Centre of Traumatology of Gdansk, Gdansk, Poland

N. Irga, MD, PhD

Department of Paediatrics, Haematology, Oncology and

Endocrinology, Medical University of Gdansk, Gdansk, Poland there were ten $(66.7 \%)$ males and five $(33.3 \%)$ females. In patients with benign and malignant tumours, the mean age for the benign group reached 44 years (range: 26-75 years old) and 54.7 years (range: $47-59$ years old) for the malignant group. In the preoperative period, symptoms such as swallowing disturbances, retrosternal pains and epigastric pains were observed. Dysphagia was the leading symptom in patients with benign and malignant oesophageal tumours.

Out of 15 patients, surgical procedure was carried out in 13 cases with rare oesophageal tumours. In the group of 11 patients, with benign tumours, ten (90.2\%) warranted surgical treatment. Three patients (75 \%) with malignant oesophageal tumours underwent an extensive Akiyama procedure of oesophageal resection. Chemo- and radiotherapy alone were performed on one (25\%) patient with oesophageal lymphoma. Postoperative complications were observed in only four (26.6\%) patients; pneumonia in the postoperative period was diagnosed in two patients who underwent surgery; infections of the postoperative wounds were diagnosed in the other two patients.

Conclusions Benign oesophageal tumours are characterized by similar clinical symptoms to malignant tumours of this organ. It is more complicated to obtain biopsy specimens for a histopathological examination in cases of benign tumours in comparison to malignant tumours. Treatment methods should be adjusted individually for each patient with a rare oesophageal tumour. For rare benign oesophageal tumours, the results of treatment are very good; however, for malignant tumours the prognosis depends on their histopathological type.

Keywords: Rare oesophageal tumours

\section{Introduction}

The most common oesophageal tumours are squamous cell carcinoma and adenocarcinoma. Other tumours are classified as rare oesophageal cancers and comprise 
only $0.1-2 \%$ [1-4]. Most commonly diagnosed benign oesophageal tumours include leiomyoma [5-7]; rare malignant oesophageal tumours include sarcomas, lymphomas, malignant melanomas and metastatic tumours of other malignant carcinomas [1-4, 8-12].

In 2008, the worldwide incidence of oesophageal cancer reached 482,000 patients and the mortality was 406,000 cases [13]. In Poland in 2008, 895 new cases of oesophageal cancer were reported and 1,116 deaths due to the disease were registered. The raw incidence rate for oesophageal cancer was 4.9 per 100,000 inhabitants for men (age-standardized 3.4) and 1.23 per 100,000 inhabitants for women (age-standardized 0.65) [14].

Besides other treatment options, surgery is always an alternative for curative intent in oesophageal carcinoma [14]. In patients with benign oesophageal tumours, enucleation of intramural lesions is the most commonly performed procedure. In exceptional cases, segmental oesophageal resections are carried out. Oesophageal diverticula and benign oesophageal tumours are more commonly treated laparoscopically [15]. Other rare methods of treatment for benign oesophageal cancer include infrequently applied alcoholization [16]. For small leiomyomas in the form of polyps, endoscopic polypectomy is a possible treatment method. However, for malignant tumours extensive oesophageal resections are performed along with thoracic or cervical anastomoses. Chemotherapy and/or radiotherapy is the treatment of choice for patients with lymphoma.

Prognosis in oesophageal cancer depends on the histopathological diagnosis. After a radical resection of oesophageal benign tumour, the disease produces no impact on the patient's life expectancy. In cases of rare malignant oesophageal tumours, life expectancy depends on the histopathological type of the tumour. Worldwide, 5-year life expectancy after radical treatment for oesophageal cancer is from 4 to $50 \%$ [14]. In Poland, 5-year life expectancy reaches $18.1 \%$ [14, 16-18]. For lymphomas, the median life expectancy is 2 years, whereas for sarcomas the median life expectancy does not exceed the period of a few months [2-4].

The aim of this study is to compare the patients with rare benign and malignant oesophageal tumours treated in the Department of Surgical Oncology, in the area of the demographic and clinical data as well as in the applied methods of treatment.

\section{Materials and methods}

Eight hundred and thirty patients with oesophageal cancer (percentage squamous cell carcinoma vs adenocarcinoma in our center was 80 and $20 \%$ respectively) were treated in the Department of Surgical Oncology between 1960 and 2005. In 15 cases (1.8\%), rare benign or malignant types of tumours were diagnosed. Patients with rare oesophageal tumours were included in the study, excluding those with squamous cell carcinoma or adenocarcinoma of the oesophagus. Demographic (age, sex) and clinical data were analysed from each patient qualified for the study, taking into account dysphagia, epigastric pain, digestive tract bleeding and retrosternal pain (after excluding cardiologic causes).

Radiological examination after barium meal (Barium sulfuricum, Polfa, Poland), gastroscopic examination with a biopsy specimen for a histopathological evaluation and computed tomography (CT) were carried out as preoperative diagnostic procedures. Not all patients had a CT scan done, as the examination was not available in the department in the years 1960-1990. In radiological examinations, exophytic and endophytic tumour types were considered pathological. The histopathological diagnosis was based on the endoscopic tumour biopsy specimen or on the postoperative microscopic evaluation.

The patients with rare oesophageal cancer were qualified for surgical treatment of thoracotomy on the right side and enucleation of benign tumours. In any situation with damage to the oesophageal wall, partial resection of the oesophagus was performed along with a thoracic or cervical anastomosis. In the patients with polyp-like lesions diagnosed as leiomyoma, endoscopic polypectomy was warranted. Chemotherapy and radiotherapy were applied for patients with lymphoma. The patients with malignant oesophageal cancer underwent an Akiyama procedure of oesophageal resection of its thoracic part [19].

\section{Results}

In the group of patients with rare oesophageal tumours $(n=15)$, there were 11 patients with benign tumours and four patients with malignant tumours.All benign tumours proved to be leiomyomas in the histopathological evaluation. For the other four patients, different malignant tumours were diagnosed in each (sarcoma, neuroendocrine carcinoma, lymphoma and squamous cell carcinoma in a patient with Crohn's disease) (Table 1).

In the group of 15 patients with rare oesophageal cancer, there were ten $(66.7 \%)$ males and five $(33.3 \%)$ females. Men were more predisposed for either benign or malignant oesophageal cancer. The male-to-female ratio was respectively: $7 / 4(\mathrm{M} / \mathrm{F})$ and $3 / 1(\mathrm{M} / \mathrm{F})$. The mean age of patients with rare oesophageal cancer was 46.9 years (range: age 26-75). In the patients with benign and malignant tumours, the mean age reached 44 years (range: age 26-75) and 54.7 years (range: age 47-59), respectively.

In the preoperative period, symptoms such as swallowing disturbances, retrosternal pains and epigastric pains were observed. Dysphagia was the leading symptom in patients with benign and malignant oesophageal tumours, in nine $(81.8 \%)$ patients with benign tumours and in all the patients with malignant tumours. The mean duration of dysphagia for the studied group was 11.4 months with a range of $0.75-24$ months; for benign tumours the mean duration of dysphagia was 13.6 months (range: 4-24 months) and for malignant tumours 


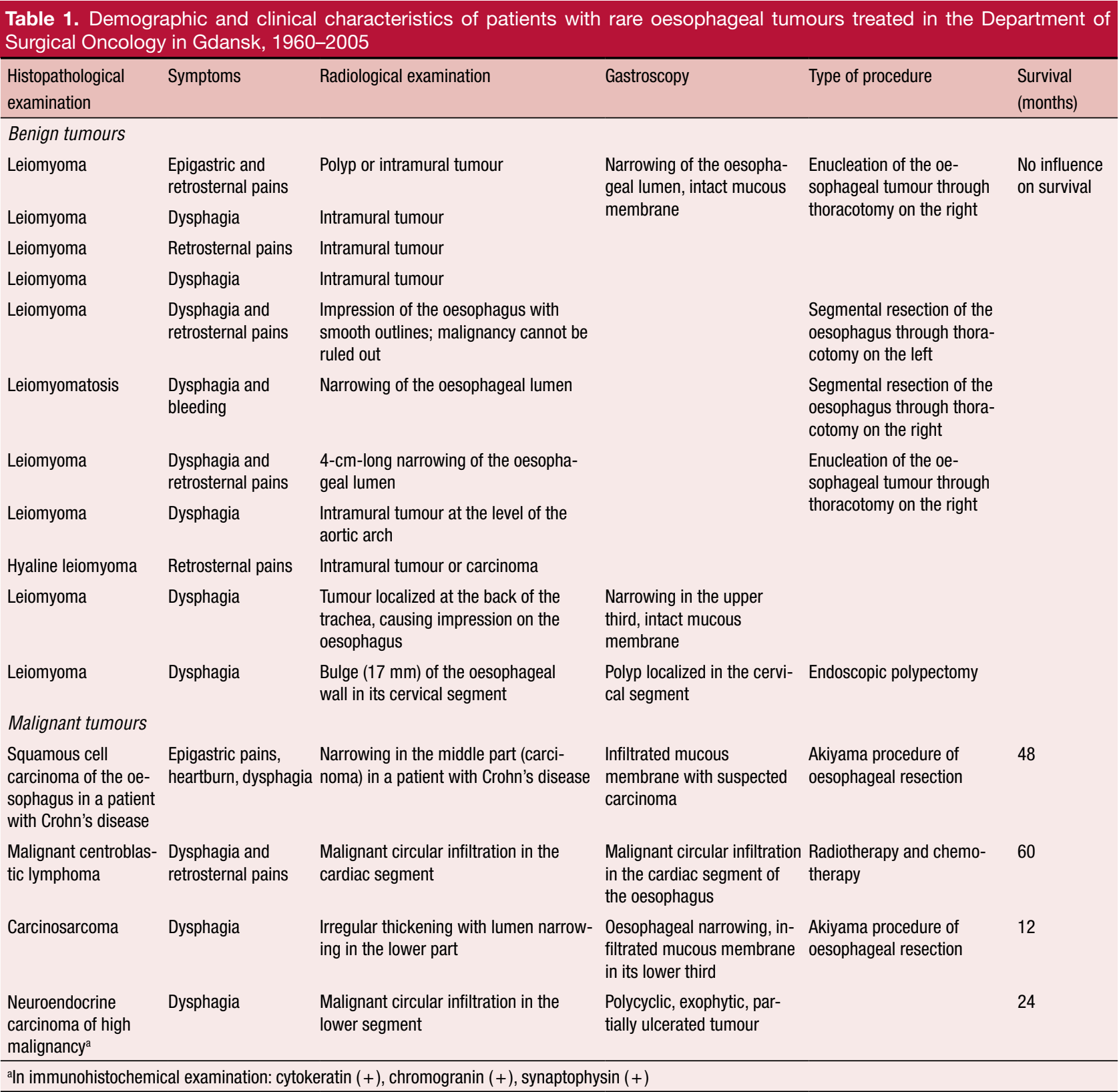

the mean duration was 5.1 months (range: 0.75-8 months). Retrosternal pain was another observed symptom and was noted in six patients ( $40 \%$ ); in five patients (45.4\%) with benign tumour and in one patient (25\%) with malignant oesophageal tumour. For the whole group of patients, the mean duration of retrosternal pain was 8 months (range: $0.75-24$ months). Epigastric pain was observed less frequently, as it was noted only in two patients (one patient with a benign tumour; one patient with a malignant tumour). Digestive tract bleeding was observed in only one patient $(6.7 \%)$ with a benign oesophageal tumour.

For the analysed group of patients, radiological examination in $11(73.3 \%)$ cases showed lesions in the oesophageal wall, whereas abnormalities in the mucosa were observed in only two $(13.3 \%)$ patients. In 10 out of
11 patients with leiomyoma, the mucosa was intact; only one patient had changes within the mucosa in the form of a polyp. For the patients with malignant oesophageal cancer, radiological examination with barium meal showed infiltrative changes in the oesophageal wall with irregularities of the mucosa. In the gastroscopic examination, all patients with benign oesophageal tumours had normal mucosa, with the exception of one patient with a polyp-like leiomyoma. However, the patients with malignant tumours had pathological changes of the mucous membrane in the form of ulceration in one (6.7 \%) patient, polyp in one $(6.7 \%)$ patient and infiltration of the oesophageal wall in two (13.3\%) patients. CT was carried out in only four patients. In the group of patients with benign tumours, in one case an intramural tumour was found and in the another case we detected a 
small polyp in the oesophageal lumen. However, for the patients with malignant tumours the examination was available in two (50\%) cases, and for each of them CT scans showed neoplastic infiltration without progressing beyond the oesophageal wall.

Thirteen out of 15 patients with rare oesophageal tumours required surgical treatment. Ten (90.2\%) out of 11 patients with benign oesophageal tumours also required surgical treatment; in eight $(72.7 \%)$ cases an enucleation of the intramural tumour was performed, and in two (18.2\%) cases a segmental oesophageal resection with thoracotomy was carried out. In the group of patients with benign tumours, segmental resection of the oesophagus was performed due to infiltration of the oesophageal wall in one case and due to iatrogenic perforation of the oesophageal wall in the other. Only in one (9\%) patient with oesophageal leiomyoma polyp, an endoscopic polypectomy was carried out. In three (75\%) patients with malignant oesophageal cancer, excessive Akiyama resections of the oesophagus were performed. Gastrointestinal bleeding was found in only one $(6.7 \%)$ patient with a benign tumor of the esophagus.

Postoperative complications were observed only in four patients out of the group of 13 who required surgery. In two (13.3\%) cases, pneumonia was diagnosed in the postoperative period (one patient with benign tumour and one patient with malignant tumour). In two (13.3\%) patients with malignant tumour of the oesophagus, an infection of the postoperative wound was observed. Infectious complications subsided after an intravenous antibiotic therapy.

For those patients with benign tumour of the oesophagus, the surgical procedure had no influence on life expectancy. However, for patients with rare malignant oesophageal tumours, the median life expectancy was 14 months (range: 12-60 months).

\section{Discussion}

Rare tumours of the oesophagus are described, in general, only in the form of case reports [1, 8-10, 15]. Collecting a larger group of patients with rare oesophageal cancer is possible only in multi-centre studies or through data acquisition from one centre over many years. The patients reported in this study are a group of 15 rare cases of oesophageal cancer collected from a department that has dealt with surgical treatment of oesophageal tumours since the early 1960s. Of those patients treated for oesophageal cancer in this period of time, rare oesophageal tumours constituted only $1.8 \%$ of diagnoses. Other authors report a similar percentage of diagnoses $[5,6]$. The most numerous group of patients in the presented clinical material was the leiomyoma group. Hamouda et al. [5], reported similar observations. Unlike other authors, in our study we did not observe patients with malignant melanoma or carcinoid tumours $[9,10]$.

In the area of clinical symptoms, there are no differences between patients with rare oesophageal tumours and patients with squamous cell carcinoma or adenocarcinoma of the oesophagus. Dysphagia is the clinical symptom that is most commonly reported from patients with oesophageal cancer [5]. In the analysed group of patients, swallowing disturbances were observed in the majority of patients with benign tumours and in all the patients with malignant tumours.

Diagnostic procedures for patients with oesophageal cancer do not differ from diagnostic procedures for patients with rare oesophageal tumours. In patients with rare oesophageal tumours, diagnosis is difficult due to discrete changes in radiological examinations with barium meal, which are observed in the majority of patients. Another difficulty in diagnostics of patients with benign oesophageal tumour is obtaining reliable material for a preoperative histopathological evaluation. According to Tay et al. [8], a transoesophageal ultrasound scan is an additional examination that improves the effectiveness of preoperative biopsies. However, the authors of this paper had no possibility to use transoesophageal ultrasound scans to evaluate the advancement of the oesophageal cancer or to obtain material for a histopathological examination, as the latter became available in the department only a few years ago. CT of the chest was a valuable complement to the diagnostics of oesophageal cancer, which led to the more normal diagnosis of intramural oesophageal tumours, especially leiomyomas. Out of the cases of intramural oesophageal tumours, in one patient the CT showed no changes in the oesophageal wall. It is generally agreed in the literature that CT is a routine examination for oesophageal cancer $[5,6]$. In the opinion of the authors of this paper, for patients with rare malignant tumours, preoperative diagnostics was easier in comparison with patients with benign intramural tumours. However, so far no such comparison has been presented.

A surgical approach is the principal method of treatment for patients with rare oesophageal cancer, and a medical approach in the form of chemotherapy, radiotherapy or endoscopic methods is exceptionally infrequent. The surgical approach that consists of enucleation of the tumour through thoracotomy is the method of choice for benign tumours; however, segmental oesophageal resection may be required in some patients. Indications for segmental oesophageal resection include large tumours tightly adhered to the mucous membrane or iatrogenic damaging of the oesophageal wall. An endoscopic enucleation of single leiomyomas has nowadays fallen out of favour, as only few oesophageal leiomyomas are pedunculated and endoscopic intramural removal of the oesophageal tumour creates risks for perforation of the oesophagus.

There are not many papers that evaluate the results of surgical treatment for the group of rare oesophageal tumours. Over the last 10 years in the literature, there has been no report of death after an enucleation of oesophageal leiomyoma; furthermore, complications such as pleural haematoma, postoperative infections or lack of tightness after an enucleation are very rare 
$[8,11,15]$. However, no differences have been observed from the results of surgical treatment and oncological treatment for rare malignant oesophageal tumours versus squamous cell carcinoma or adenocarcinoma of the oesophagus.

\section{Conclusion}

The comparison of patients with rare benign and malignant oesophageal tumours enabled the authors to show differences in the area of preoperative diagnostics and treatment of the patients. The patients with benign tumours have similar clinical symptoms to the patients with malignant tumours, although it is more difficult to obtain a reliable endoscopic biopsy specimen for a histopathological evaluation. If this procedure fails, then fine needle aspiration can be considered as a method to achieve a preoperative diagnosis. The treatment methods and long-term survival seem to be significantly different between the groups of patients with benign and malignant tumours.

\section{Conflict of interest}

The authors declare that there is no actual or potential conflict of interest in relation to this article.

Open Access This article is distributed under the terms of the Creative Commons Attribution License which permits any use, distribution, and reproduction in any medium, provided the original author(s) and the source are credited.

\section{References}

1. Suzuki H, Nakanishi Y, Taniguchi H, Shimoda T, Yamaguchi H, Igaki H, Tachimori Y, Kato H. Two cases of early-stage esophageal malignant melanoma with long-term survival. Pathol Int. 2008;58:432-5.

2. Chung JJ, Kim MJ, Kie JH, Kim KW. Mucosa-associated lymphoid tissue lymphoma of the esophagus coexistent with bronchus-associated lymphoid tissue lymphoma of the lung. Yonsei Med J. 2005;46:562-6.

3. Iwaya $T$, Maesawa $C$, Uesugi $N$, Kimura $T$, Ogasawara $S$, Ikeda K, Kimura Y, Mitomo S, Ishida K, Sato N, Saito K, Masuda T. True carcinosarcoma of the esophagus. Dis Esophagus. 2006;19:48-52.

4. Gaur D, Kishore S, Saini S, Pathak V. Carcinosarcoma of the oesophagus. Singapore Med J. 2008;49:283-5.
5. Hamouda AH, Chisholm E. Endoscopic alcohol injection as a tretment modality for oesophageal leiomyoma. European J Surg Oncol. 2008;34:122-4.

6. Palanivelu C, Rangarajan M, Senthilkumar R, Velusamy M. Combined thoracoscopic and endoscopic management of mid-esophageal benign lesions: use of the prone patient position - Thoracoscopic surgery for mid-esophageal benign tumors and diverticula. Surg Endosc-Ultras. 2008;22:250-4.

7. Didkowska J, Wojciechowska W, Zatoński W. Nowotwory złosliwe w Polsce w 2008 roku. 2010.

8. Tay YC, Ng CT, Lomanto D, Ti TK. Leiomyoma of the oesophagus managed by thoracoscopic enucleation. Singapore Med J. 2006;47:901-3.

9. Lu TJ, Huang TW, Lee SC. Primary malignant melanoma of the esophagus. Ann Saudi. 2008;28:458-60.

10. Gupta V, Kochhar R, Sinha SK, Das A. Primary malignant melanoma of the esophagus long-term survival after radical resection. J Thorac Oncol. 2009;4:1180-2.

11. Boran C, Sengul N, Balaban YH, Gurel S. Multinodular leiomyoma of the esophagus with internodular hydropic degeneration and bulbous serosal protrusions similar to cotyledonoid uterine leiomyoma. Dis Esophagus. 2007;20:187-9.

12. Maggiani F, Debiec-Rychter M, Ectors N, Lerut A, Scolot R. Primary epithelioid sarcoma of the oesophagus. Virchows Arch. 2007;451:835-8.

13. Ferlay J, Shin H, Bray F, Forman D, Mathers C, Parkin D. Estimates of worldwide burden of cancer in 2008: GLOBOCAN 2008. Inter J Cancer. 2010;127:2893-917.

14. Zielinski J, Swierblewski M, Kruszewski WJ, Jaworski R, Haponiuk I, Irga N, Kopacz A, Jaskiewicz J. A single-center experience in surgical treatment of squamous cell oesophageal carcinoma in the years 1970-2007. Kardiochirurgia I Torakochirurgia Polska. 2011;8:71-6.

15. Mainprize KS, Dehn TCB. Laparoscopic management of pseudoachalasia, esophageal diverticulum, and benign esophageal stromal tumor. Dis Esophagus. 2001;14:73-5.

16. Earlam R, Cunha-Melo JR. Oesophageal aquamous cell carcinoma: a critical review of surgery. Br J Surg. 1980;67:381-90.

17. Hulscher JB, van Sandick JW, de Boer AG, Wijnhoven BP, Tijssen JG, Fockens P, Stalmeier PF, Ten Kate FJ, Van dekken H, Obertop H, Tilanus HW, van Lanschot JJ. Extended transtrhoracic resection compared with limited transhiatal resection for adenocarcinoma of the esophagus. N Engl J Med. 2002;347:1662-9.

18. Altorki N, Skinner D. Should en block esophagectomy be the standard of care for esophageal carcinoma? Ann Surg. 2001;234:581-7.

19. Akiyama H, Tsurumaru M, Udagawa H, Kajlyama Y. Radical lymph node dissection for cancer of the thoracic esophagus. Ann Surg. 1994;220:364-72. 